\title{
Parotid gland tumours in a West Indian population: Comparison to world trends
}

\author{
MICHAEL J. RAMDASS, KHEMANAND MAHARAJ, JUSTIN MOOTEERAM, \\ WENDELL DWARIKA, CLYDE TILLUCKDHARRY and SHAHEEBA BARROW
}

\begin{abstract}
Department of Clinical Surgical Sciences, Port-of-Spain General Hospital, University of the West Indies, Port-of-Spain, Trinidad and Tobago, West Indies
\end{abstract}

Received August 20, 2014; Accepted October 3, 2014

DOI: $10.3892 / \mathrm{mco} .2014 .437$

\begin{abstract}
The epidemiology of parotid gland tumours in Trinidad and Tobago and the wider Caribbean is currently unknown. Therefore, an analysis of the pathological records was conducted to determine the pattern of this disease in Trinidad and Tobago. A retrospective analysis was conducted on all parotid gland tumours and the demographic and histological data were analysed. Data from 60 cases were collected over a period of 8 years (October, 2003 to February, 2012), including 56 primary and 4 secondary tumours (1 basal cell carcinoma and 3 metastatic tumours). The patients included 31 men and 29 women, with a mean age of 48.7 years and an age range of 21-73 years (peak age, 51-60 years). The surgical interventions included 53 superficial parotidectomies, 6 radical parotidectomies and 1 biopsy. Of the 56 primary tumours, 41 were benign [34 pleomorphic adenomas and 7 Warthin's tumours (adenolymphomas)], accounting for $73.2 \%$ of the cases. The malignant lesions included 6 squamous cell carcinomas, 3 mucoepidermoid carcinomas, 2 acinic cell carcinomas, 2 adenoid cystic carcinomas, 1 anaplastic carcinoma and 1 papillary carcinoma, accounting for $26.8 \%$ of the total cases, without any age predominance. The pattern of disease distribution was similar to that indicated by worldwide data, with benign primary lesions accounting for $\sim 80 \%$ of the cases (pleomorphic adenomas, 80\% and Warthin's tumours, 20\%). The most common carcinomas were mucoepidermoid and adenoid cystic types, as indicated by worldwide data; however, in our series, squamous cell carcinoma was the most common type, followed by mucoepidermoid, acinic cell and adenoid cystic carcinomas. The present study will hopefully provide useful information on parotid pathology in Trinidad and Tobago and encourage further research in this field.
\end{abstract}

Correspondence to: Dr Michael J. Ramdass, Department of Clinical Surgical Sciences, Port-of-Spain General Hospital, University of the West Indies, Charlotte Street, Port-of-Spain, Trinidad and Tobago, West Indies

E-mail: jimmyramdass@gmail.com

Key words: parotid tumours, West Indies, Caribbean

\section{Introduction}

The word parotid is derived from the greek word 'parotis', which means para (near) and otis (ear). The parotid gland has been extensively investigated and there are numerous published studies on the pathology of this gland worldwide. It was estimated that salivary gland tumours comprise $\sim 3-10 \%$ of all neoplasms of the head and neck (1), with an incidence estimated at $0.4-13.5 \%$ annually per 100,000 individuals worldwide (2). The majority ( $80 \%$ ) of these tumours originate in the parotid gland, with an incidence of $66-80 \%$ for benign and $20-34 \%$ for malignant lesions. A recent study conducted by Shrestha et al (3) at B.P. Koirala Memorial Cancer Hospital in Nepal, reported these new statistics on salivary gland tumours based on a total of 34,978 biopsies. The highest incidence for benign lesions was in the 3rd-4th and for malignant lesions in the 4th-5th decades of life, with a male predominance (63.6\% of all cases). Mucoepidermoid carcinoma was the most common malignant tumour of the parotid gland, accounting for $23.6 \%$ of all malignant salivary gland tumours in that series, followed by adenoid cystic carcinoma (9\%), acinic cell carcinoma (7.2\%), adenocarcinoma not otherwise specified (6.3\%), carcinoma ex pleomorphic adenoma (5.4\%), unclassified tumours (4.5\%), squamous cell carcinoma (3.6\%), basal cell carcinoma (1.8\%), polymorphous low-grade adenocarcinoma (1.8\%) and metastatic undifferentiated carcinoma $(1.8 \%)$. Survival as quoted by the American Cancer Society varies depending on stage, with a 5-year survival rate of $91 \%$ for stage I, $75 \%$ for stage II, $65 \%$ for stage III and 39\% for stage IV disease (4). The prognosis is extremely good in children, with a survival rate of $\sim 100 \%$. As regards the available literature in the Caribbean region, there are only a few studies from Jamaica, South America and Cuba. To the best of our knowledge, this is the first study on parotid gland pathology from Trinidad and Tobago and it may serve as a platform for further research and development in this area.

\section{Materials and methods}

Data collection. Retrospective data on all the cases of parotid tumour surgery between October, 2003 and February, 2012 were collected from the electronic records of the Department of Pathology at the Port-of-Spain General Hospital (POSGH), 


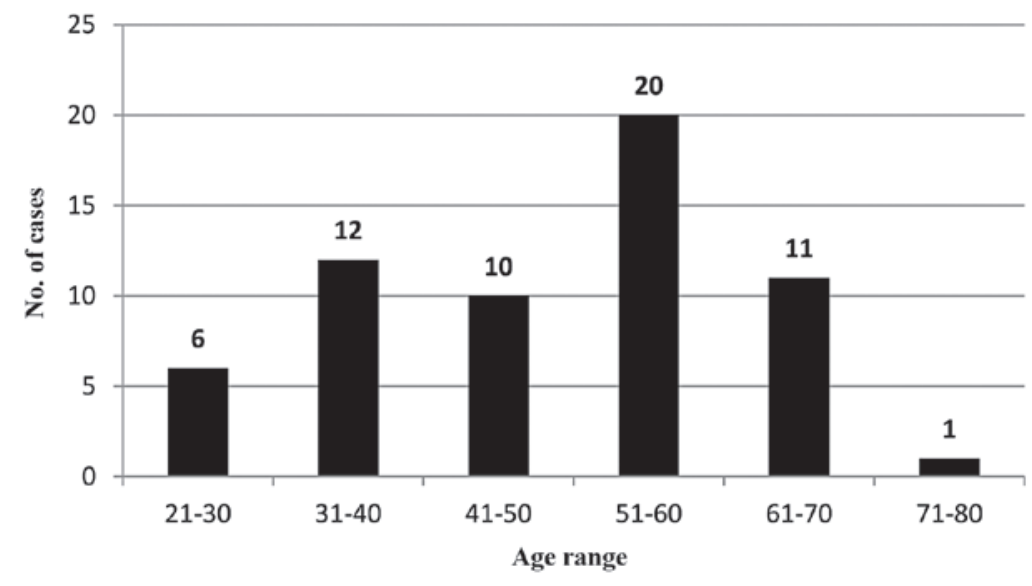

Figure 1. Bar chart presenting the number of cases per age group.

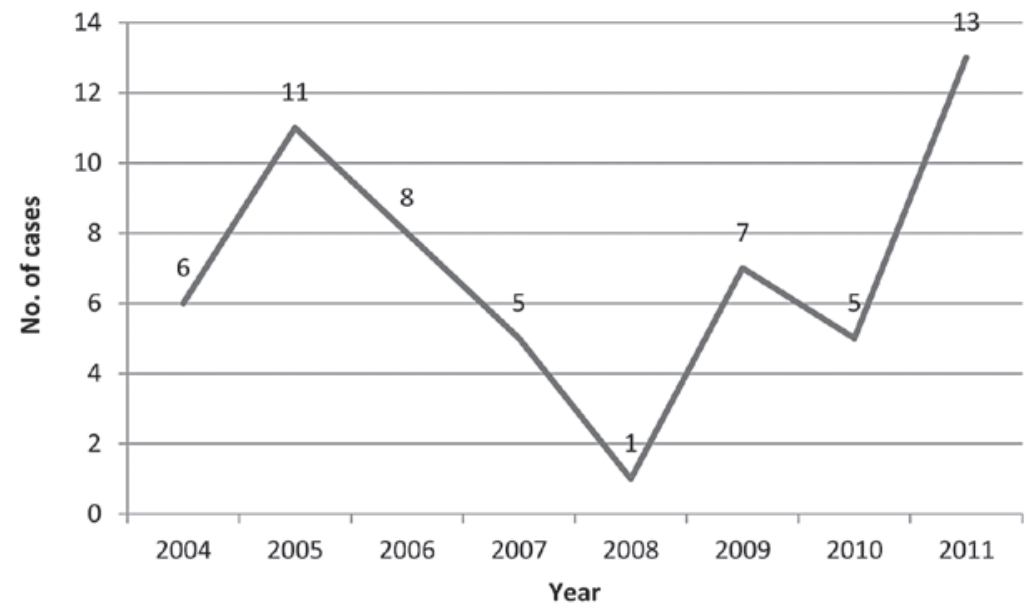

Figure 2. Chart presenting trends with relation to the number of primary cases reported annually $(\mathrm{n}=56)$.

Trinidad and Tobago. Demographic information regarding date of surgery, patient age and gender, hospital of origin, morphological and histological characteristics of the specimen, were collected and retrospectively analyzed. Pathological data from POSGH, Sangre Grande District General Hospital (SGH) and Scarborough Regional Hospital (SRH) in Tobago were also included in this study.

Ethics approval was granted from the relevant authorities and the data were analyzed using SPSS ${ }^{\circledR}$ statistics, version 20 (IBM SPSS, Armonk, NY, USA).

Types of tumours. Histological information was collected and classified by type of tumour. The benign lesions included pleomorphic adenoma, Warthin's tumour (adenolymphoma) and monomorphic adenoma and the malignant tumours included mucoepidermoid carcinoma, adenocarcinoma, acinic cell carcinoma and squamous cell carcinoma.

\section{Results}

Patients. Data from 60 parotid tumour patients between October, 2003 and February, 2012 were retrospectively collected from the pathology records at POSGH, Trinidad and Tobago. Our sample comprised 56 primary lesions, 1 basal cell carcinoma of the skin infiltrating the gland and 3 metastatic tumours. The patients included 31 men and 29 women, with a mean age of 48.7 years, a median of 51.5 years and a mode of 56 years (range, 21-73 years).

Age distribution and annual incidence. The age range distribution was as follows: 21-30, 6 (10\%); 31-40, 12 (20\%); 41-50, 10 (13.3\%); 51-60, 20 (33.3\%); 61-70, 11 (18.3\%); and $71-80,1$ (1.7\%) (Fig. 1). The number of new primary cases per year was as follows: 2004, 6; 2005, 11; 2006, 8; 2007, 5; 2008, 1; 2009, 7; 2010, 5; and 2011, 13 (Fig. 2).

Surgical approach and tumour types. Of the 60 cases, $53(88.3 \%)$ were from POSGH and 7 from SGH, whereas there were no cases from SRH. The surgical procedures included 53 superficial parotidectomies, 6 radical parotidectomies and 1 parotid biopsy. The primary tumours comprised 56 cases in total, excluding 1 basal cell carcinoma and 3 metastatic lesions. The benign lesions included 34 pleomorphic adenomas and 7 Warthin's tumours, accounting for $73.2 \%$ of the 56 primary tumours.

Benign lesions. For pleomorphic adenomas, the mean patient age was 47 years (range, 27-73 years). The peak age groups 
affected included the 3rd and 5th decades of life, accounting for 29 and $32 \%$ of patients, respectively, with female patients accounting for $65 \%$ of these cases.

As regards Warthin's tumours, the age range was 44-68 years, with a mean of 55 years. The peak age groups affected included the 4 th, 5 th and 6 th decades of life, accounting for $28.6 \%$ of cases per decade. Males were predominantly affected, accounting for $86 \%$ of these cases.

Malignant lesions. The malignant lesions included 6 squamous cell carcinomas, 3 mucoepidermoid carcinomas, 2 acinic cell carcinomas, 2 adenoid cystic carcinomas, 1 anaplastic carcinoma and 1 papillary carcinoma, accounting for $26.8 \%$ of all the lesions.

\section{Discussion}

Parotid gland pathology has been well described and documented in the literature, with $80 \%$ of all primary tumours being benign and $20 \%$ malignant. Of the benign lesions, pleomorphic adenomas account for $80 \%$ and Warthin's tumours for $20 \%$ of the cases. These figures may vary in different regions, but are generally confined within a certain range. The most common malignant parotid tumours worldwide are reportedly mucoepidermoid and adenoid cystic carcinomas (5-7). Other malignant tumours of the parotid gland include acinic cell carcinoma, carcinoma ex pleomorphic adenoma, adenocarcinoma (arising from the ductal epithelium of the parotid gland), squamous cell carcinoma (arising from the parenchyma of the parotid gland) and undifferentiated carcinoma.

A study conducted by Catania et al (8) in Italy investigated 336 patients, 239 of whom had benign and 65 malignant lesions. Of the benign lesions, $55 \%$ were pleomorphic adenomas and $36 \%$ were Warthin's tumours, whereas the majority of the malignant lesions (29\%) were mucoepidermoid carcinomas.

A study conducted by Chung et al (9) in Singapore documented the epidemiology of parotid gland tumours in an Asian population over a period of 10 years. A total of 289 patients were investigated, of whom 136 had pleomorphic adenomas and $73(25 \%)$ Warthin's tumours (7 bilateral), with a ratio of Warthin's tumours to pleomorphic adenomas of 1:9. The racial distribution of Warthin's tumours exhibited an increased incidence among Chinese patients and a reduced incidence among Malays and Indians. It was hypothesized that the lower incidence among ethnic groups with darker skin suggested that concomitant genetic factors other than environmental factors alone affected tumorigenesis. Smokers exhibited a 40-fold higher risk of developing a Warthin's tumour compared to non-smokers.

Another study conducted by Gunn et al (10) in Northumberland investigated 376 new cases of parotid tumours over a period of 5 years, with 28 recurrent cases. The incidence of new parotid tumours was 2.4 per 100,000 and of pleomorphic adenomas 1.5 per 100,000 cases per annum.

An interesting study, conducted by Massoud et al (11) in Lebanon, reported on the etiological aspects of 175 parotidectomies. The authors reported that $80 \%$ of the lesions were benign and $20 \%$ were malignant, with an increase in malignancy rates with increasing age. The mixed tumour rate was $31 \%$, with $69 \%$ of the cases comprising haemangiomas, tuberculomas, salivary cysts, chronic parotiditis and Warthin's tumours.

Of note, Manifold et al (12) conducted a study on parotid gland tumours in children and reported that $50 \%$ of all tumours were malignant; therefore, all parotid lumps in children should be considered as malignant until proven otherwise. There was also a report by McShane et al (13) on adenoid cystic carcinoma arising in the context of AIDS-related complex; this type of tumour is currently more commonly encountered, due to the increasing incidence of HIV infection.

As regards local data, very few studies have been published within the West Indies, with no documented data from Trinidad and Tobago. A literature search identified an article by Shah et al (14) published in the West Indian Medical Journal in 1990. Between 1958 and 1989, the Jamaica Cancer Registry recorded 491 cases of benign and malignant salivary gland tumours, including 18 cases of Warthin's tumour (3.7\%), with a male:female ratio of 5:1. Obbenson et al (15) also conducted an analysis on fine-needle aspiration cytology in 2001. Additionally, there have been 3 studies from Cuba detailing the pathology of the parotid and other salivary glands (16-18).

The present study on 60 patients with parotid gland tumours in a mixed West Indian population, composed of $40 \%$ East Indians, 38\% Afro-Caribbeans, 20\% mixed and $<2 \%$ Caucasians, Chinese and Arabs, revealed an interesting profile for these tumours.

There were 56 primary and 4 secondary lesions ( 1 basal cell carcinoma and 3 metastatic tumours). The male:female ratio was $1: 1$, with a mean age of 48.7 years, a median of 51.5 years and a mode of 56 years (range, 21-73 years). There were no pediatric cases and no definitive confirmation of AIDS-related complex, although this condition may have been present but overlooked.

The benign lesions included 34 pleomorphic adenomas, and 7 Warthin's tumours, accounting for $73.2 \%$ of the 56 primary tumours. The malignant lesions included 6 squamous cell carcinomas, 3 mucoepidermoid carcinomas, 2 acinic cell carcinomas, 2 adenoid cystic carcinomas, 1 anaplastic carcinoma and 1 papillary carcinoma, accounting for $26.8 \%$ of all the primary lesions. The most common carcinomas are reportedly the mucoepidermoid and adenoid cystic types; however, squamous cell carcinomas were the most commonly encountered malignant parotid tumours in our series.

This study may provide useful information on parotid gland pathology in Trinidad and Tobago and, by extension, the West Indies, encouraging further research in this field.

\section{Acknowledgements}

We herein acknowledge the tireless efforts of Dr Neville Jankey FRCPath, the Senior Pathologist at POSGH over several decades and one of the main contributors to this database. This study received no specific grant from any funding agency in the public, commercial or not-for-profit sectors.

\section{References}

1. Ansari MH: Salivary gland tumors in an Iranian population: a retrospective study of 130 cases. J Oral Maxillofac Surg 65: 2187-2194, 2007. 
2. Jones AV, Craig GT, Speight PM and Franklin CD: The range and demographics of salivary gland tumours diagnosed in a UK population. Oral Oncol 44: 407-417, 2008.

3. Shrestha S, Pandey GK, Pun CB, Bhatta R and Shahi R: Histopathological pattern of salivary gland tumors. J Pathol Nepal 4: 520-524, 2014

4. American Cancer Society and salivary gland cancer. http://www. cancer.org/cancer/salivaryglandcancer/detailedguide/. Accessed, September 16, 2014.

5. Gore DO, Annamunthodo $\mathrm{H}$ and Harland A: Tumours of salivary gland origin. Surg Gynecol Obstet 119: 1290-1296, 1964.

6. Gardner AF, Siegler HR and Spire ED: A study of one hundred and seventy-three instances of pleomorphic adenomas of the salivary glands. Am Surg 30: 539-548, 1964.

7. Butler EC: The management of tumours of the parotid gland, based on 373 cases seen at the London Hospital between 1943-1958. Bull Soc Int Chir 23: 10-16, 1964.

8. Catania A, Falvo L, D'Andrea V, et al: Parotid gland tumours. Our experience and a review of the literature. Chir Ital 55: $857-864,2003$

9. Chung YF, Khoo ML, Heng MK, et al: Epidemiology of Warthin's tumour of the parotid gland in an Asian population. Br J Surg 86: 661-664, 1999.

10. Gunn A and Parrott NR: Parotid tumours: a review of parotid tumour surgery in the Northern Regional Health Authority of the United Kingdom 1978-1982. Br J Surg 75: 1144-1146, 1988.
11. Massoud E and Tarabay F: Parotid tumours. Only 31\% of mixed tumours in one hundred and seventy-five parotidectomies. Sem Hop 58: 1448-1455, 1982 (In French).

12. Manifold DK and Thomas JM: Parotidectomy in childhood - with a review of the literature. Eur J Surg Oncol 20: 549-552, 1994.

13. McShane DP, Vellend H and Dayal VS: AIDS, otolaryngology and a case of adenoid cystic carcinoma of the parotid arising in a patient with the AIDS-related complex. J Otolaryngol 16: 10-15, 1987.

14. Shah D, Williams E and Brooks SE: Warthin's tumour in Jamaica. Incidence, electron microscopy and immunoenzyme studies. West Indian Med J 39: 225-232, 1990.

15. Obenson K and East J: Fine needle aspiration biopsy in Western Jamaica: preliminary observations. Cytopathology 12: 129-130, 2001.

16. Juarbe C, Longo F, Riera I and Urdaz V: Parotidectomy in an urban community hospital. Bol Asoc Med PR 81: 427-429, 1989.

17. Estrada Sarmiento M and Pinilla González R: Tumors of the parotid gland. Rev Cubana Estomatol 23: 221-227, 1986 (In Spanish).

18. Urbizo Velez J and Moreira Diaz E: Salivary gland tumors. A study of 155 cases. Rev Cubana Estomatol 12: 137-143, 1975 (In Spanish). 